\title{
APURAÇÃO E EVIDENCIAÇÃO DOS RESULTADOS DAS INSTITUIÇÕES DE ENSINO SUPERIOR COM CERTIFICADO DE ENTIDADE BENEFICENTE DE ASSISTÊNCIA SOCIAL*
}

\author{
EMANOEL MARCOS LIMA \\ Professor da Universidade Católica Dom Bosco - MS \\ e da Sociedade de Ensino Superior Estácio de Sá - MS \\ E-mail: emanoel@ucdb.br
}

\author{
CARLOS ALBERTO PEREIRA \\ Professor Doutor do Depto. de Contabilidade e Atuária da FEA/USP - SP \\ E-mail: cap@usp.br
}

\section{RESUMO}

O objetivo deste trabalho é contribuir com o aperfeiçoamento das informações contábeis para a gestão das Instituições de Ensino Superior com Certificado de Entidade Beneficente de Assistência Social - IESCEBAS, por meio da proposição de um modelo para apuração e evidenciação do resultado com o Certificado de Entidade Beneficente de Assistência Social. Os gestores, o governo e a sociedade necessitam de informações úteis e confiáveis sobre os resultados com o CEBAS para tomada de decisões. Porém, conforme se constatou por meio de pesquisa de campo e pela análise das demonstrações contábeis de algumas instituições, a prática adotada e a norma editada pelo Conselho Federal de Contabilidade não são adequadas para fornecer informações sobre os resultados com o certificado. A partir desta constatação e à luz de conceitos da teoria contábil, propõe-se um modelo de apuração e evidenciação dos resultados com o certificado das IESCEBAS, de modo a subsidiar os gestores, o governo e a sociedade em suas decisões. Ao final, analisam-se os resultados da aplicação do modelo ao caso real de uma Instituição de Ensino Superior.

Palavras-chave: Contabilidade, Ensino Superior, Filantropia, Custos de Oportunidade.

\section{ABSTRACT}

This study aims to contribute to the supply of better financial information for the management of Higher Education Institutions with a Philanthropy Certificate - IESCEBAS by proposing a model for verifying and disclosing the income obtained through the Philanthropy Certificate. Managers, the government and society need useful and trustworthy information about the income obtained through the CEBAS with a view to decision making. However, as we observed from the field research and the analysis of some institutions' financial statements, the adopted practices and the established accounting standard are inadequate to provide information on the results obtained through the certificate. On the basis of this observation and in view of theoretical accounting concepts, we propose a model for verifying and disclosing the income obtained through the Philanthropy Certificate, so as to assist the managers, government and society in making decisions. Finally, we analyze the results achieved by the application of the proposed model to one Higher Education Institution.

Keywords: Accounting, Higher Education, Philanthropy, Opportunity Costs.

*Artigo elaborado com base na Dissertação Mestrado defendida em 2003 e premiada como a melhor dissertação do ano do Programa de Pós-Graduação em Controladoria e Contabilidade da FEA-USP. 


\section{INTRODUÇÃO}

O tema ensino superior sempre esteve presente nas propostas de todos os governos e não poderia ser diferente haja vista sua importância para o desenvolvimento do país.

Segundo a Constituição Federal de 1988, o ensino superior será desenvolvido "com a colaboração da sociedade", no sentido de que essa também possa contribuir para a formação do cidadão. O Estado, ao solicitar a participação da sociedade civil na formação das pessoas, reconhece a sua incapacidade em atender a todas as necessidades educacionais dos indivíduos. Para tanto, através de leis de incentivos favorece a sociedade, no sentido de proporcionar o ensino a um custo menor.

Atualmente, no Brasil o ensino superior é oferecido através de: instituições públicas, que são administradas pelos governos; instituições privadas com fins lucrativos, que, igualmente às demais empresas, estão obrigadas a recolher impostos e contribuições; instituições privadas sem fins lucrativos, as quais, se cumprirem os requisitos legais, são imunes aos impostos federais, estaduais, municipais e distrital. Nessa última categoria, observa-se a existência de dois tipos de instituições: aquelas que gozam da referida imunidade constitucional, sem que Ihes sejam exigidas qualquer contrapartida de prestação de serviços ao Estado, mas estão obrigadas ao recolhimento das contribuições sociais; e aquelas que, além dessa imunidade constitucional, são isentas do recolhimento das contribuições para a seguridade social, por possuírem o "certificado de entidade beneficente e de assistência social" fornecido pelo CNAS, obrigando-se a prestar serviços gratuitos à comunidade. Essas entidades são conhecidas como "filantrópicas". De acordo com o Inciso VI do Art. 3ํ do Decreto oㅜ 2536, de 6 de Abril de 1998, a isenção das filantrópicas está condicionada à aplicação de pelo menos $20 \%$ de sua receita bruta total em gratuidades. É importante lembrar que essa isenção refere-se apenas à parcela das contribuições sociais que competem ao empregador e que o valor a que corresponde esse percentual nunca poderá ser inferior ao valor das contribuições sociais não recolhidas.

Constata-se, pois, que, do ponto de vista do governo, a isenção das filantrópicas não se caracteriza como um benefício concedido sem contrapartida, mas, sim, como uma transferência de valores entre o governo e a iniciativa privada. Ao conceder isenções, o governo renuncia à entrada de novos recursos aos cofres públicos, esperando, em troca, que as instituições beneficiadas prestem serviços gratuitos à população carente. Por outro lado, do ponto de vista das instituições filantrópicas, as isenções se constituem em benefícios, enquanto a prestação de serviços gratuitos representa um ônus. Desse modo, fica claro que, se para um lado a conta for positiva, para o outro ela será negativa.

Para que as Instituições de Ensino Superior com Certificado de Entidade Beneficente de Assistência Social - IESCEBAS - possam fazer jus aos benefícios (isenções das contribuições para a seguridade social), elas incorrerão em custos (aplicações em gratuidades) necessários para o cumprimento do percentual estabelecido na legislação.

O Ministério da Educação e Cultura - MEC avalia que falta transparência por parte das filantrópicas, de forma que o governo não tem informações sobre quanto e como essas instituições estão aplicando os recursos estabelecidos em lei. Os procedimentos contábeis adotados por essas instituições não têm sido capazes de demonstrar a real aplicação dos recursos em função dos benefícios recebidos. Os critérios e procedimentos contidos na NBC T 10.19 (CFC, 2000), apesar de contemplarem as situações que ocorrem nas IESCEBAS, com relação aos benefícios fiscais e gratuidades, contrariam os princípios fundamentais de Contabilidade, principalmente no que diz respeito ao princípio da competência.

Diante das situações apresentadas e da necessidade de que a Contabilidade produza informações úteis para os gestores, o governo e a sociedade, apresentamse as seguintes questões sobre o tema em estudo: (i) os certificados (CEBAS) geram resultados para as instituições que os possuem? (ii) se geram, esses resultados estão sendo apurados e evidenciados pela Contabilidade? (iii) a informação contábil sobre os resultados gerados pelo certificado é relevante para a gestão dos recursos envolvidos? Com base nos argumentos que serão apresentados ao longo deste trabalho, demonstra-se que os certificados geram resultados para as instituições que os possuem, mas, apesar de ser uma informação relevante para a gestão, esses resultados não estão sendo apurados e evidenciados pela Contabilidade.

Desse modo, formulou-se a seguinte questão que orienta o presente estudo: "como a Contabilidade pode apurar e evidenciar os resultados com o certificado 
visando subsidiar a gestão das IESCEBAS, o governo e a sociedade na tomada de decisão"? Como uma resposta a essa questão, assume-se, preliminarmente, a seguinte hipótese: o certificado (CEBAS) gera resultados para as instituições que o possuem, os quais podem ser apurados pela Contabilidade através do confronto entre os custos (beneficências) e benefícios (isenção das contribuições sociais) e evidenciados nas demonstrações contábeis das IESCEBAS. Se confirmada essa hipótese, então constata-se a necessidade de aperfeiçoamento das informações contábeis, de modo a subsidiar a gestão das IESCEBAS, governo e sociedade na tomada de decisão.

Nesse contexto, o objetivo deste trabalho é contribuir com o aperfeiçoamento das informações contábeis para a gestão das IESCEBAS, por meio da proposição de um modelo de apuração e evidenciação do resultado com o Certificado de Entidade Beneficente de Assistência Social.

O método utilizado na pesquisa foi o hipotético dedutivo defendido por Popper (1993), visto que se parte de um problema, estabelece-se uma hipótese geral e procura-se testá-la visando corroborá-la ou não e, por fim, é proposta uma solução, num ambiente específico.

Para se constatar a existência do problema objeto deste estudo, realizou-se uma pesquisa exploratória, por meio da aplicação de questionários junto aos contabilistas das IESCEBAS. À luz das evidências da pesquisa exploratória, realizou-se pesquisa bibliográfica e documental, visando sustentar o desenvolvimento de uma proposta de solução para o problema identificado. Ao final, a solução proposta foi aplicada ao caso real de uma instituição de ensino superior portadora do certificado, com a finalidade de verificar a sua viabilidade prática e, desse modo, comprovar a hipótese assumida.

\section{CARACTERIZAÇÃO DAS INSTITUIÇÕES DE ENSINO SUPERIOR COM CERTIFICADO DE ENTIDADE BENEFICENTE DE ASSISTÊNCIA SOCIAL - IESCEBAS}

Diferentemente das instituições de ensino superior com fins lucrativos, as IESCEBAS não visam ao acúmulo de riquezas com a finalidade de remunerar o capital dos fundadores, mantenedores etc., e, sim, ao cumprimento dos seus objetivos sociais e à continuidade da instituição. Entretanto, para essa realização, tais instituições necessitam de recursos materiais, humanos, financeiros e tecnológicos, entre outros. A principal fonte de recursos é a mensalidade escolar paga por seus alunos. Essas instituições, apesar de serem sem fins lucrativos, sofrem concorrência tanto na obtenção de recursos quanto na colocação de seus produtos e serviços a seus clientes, e precisam assegurar a sua continuidade para alcançar seus objetivos.

Essas instituições fazem parte do Terceiro Setor, entretanto não se caracterizam pela participação voluntária, pois suas atividades são desenvolvidas por funcionários remunerados pela prestação dos serviços, sendo possível, dessa forma, a contratação e remuneração de funcionários para desempenharem as funções necessárias para o desenvolvimento das atividades.

O produto final das instituições de ensino superior sem finalidades lucrativas é a transformação de pessoas, contribuindo, desse modo, através do seu produto, para a mudança da sociedade como um todo.

Essas instituições contam com dispositivos constitucionais que lhes asseguram a não incidência de impostos sobre, por exemplo, a renda e os serviços prestados. Sem entrar no mérito das discussões jurídicas que ocorrem sobre o tema, observa-se que é vedado à União, aos Estados, ao Distrito Federal e aos Municípios, pela Constituição Federal, instituir impostos sobre as entidades apontadas no art. 150, $\mathrm{VI}$, "c", que preencherem os requisitos estabelecidos em lei. Os benefícios estendem-se somente aos impostos, compreendendo:

- Imposto de Renda;

- Imposto Sobre Propriedade de Veículo Automotor - IPVA;

- Imposto Sobre a Transmissão Causa Mortis e Doação de Quaisquer Bens ou Direitos - ITCD;

- Imposto Sobre Circulação de Mercadorias e Serviços - ICMS;

- Imposto Sobre Serviços de Qualquer Natureza - ISSQN;

- Imposto Predial Territorial Urbano - IPTU;

- Imposto Sobre Transmissão de Bens Imóveis e de Direitos a Eles Relativos - ITBI.

$\mathrm{O} \S 7^{\circ}$ do inciso III do art. 195 da CF/88 estabelece que: "São isentas de contribuição para a seguridade social às entidades beneficentes de assistência social que atendam às exigências estabelecidas em lei". 
As instituições de ensino superior sem finalidades lucrativas, desde que cumpridos os requisitos estabelecidos no Decreto $\mathrm{n}^{\circ} \mathrm{2}$ 2.536, são consideradas entidades beneficentes de assistência social, portanto isentas das contribuições para a seguridade social de responsabilidade da empresa, sendo que os descontos efetuados dos funcionários, autônomos e empresas, devem ser recolhidos normalmente.

De acordo com os art. 22 e 23 da Lei no 8.212, as contribuições destinadas à seguridade social são:

- Cota patronal do INSS;

- Contribuição para financiamento da seguridade social - Cofins;

- Contribuição social sobre o lucro líquido - CSLL.

Assim, a partir do que foi exposto, apresentase abaixo quadro resumo dos benefícios usufruídos pelas IESCEBAS nas esferas Federal, Estadual e Municipal:

\begin{tabular}{l|l} 
ESFERAS & BENEFÍCIOS \\
FEDERAL & Imposto de Renda, Cofins, CSLL e INSS \\
\hline ESTADUAL & ICMS, IPVA e ITCD \\
\hline MUNICIPAL & ISSQN, IPTU e ITBI \\
\hline \multicolumn{2}{c}{ Quadro 1 - Benefícios Fiscais }
\end{tabular}

\section{BENEFÍCIOS FISCAIS E PROCEDIMENTOS CONTÁBEIS ADOTADOS PELAS IESCEBAS}

Com o objetivo de se verificar o entendimento das IESCEBAS com relação aos benefícios fiscais usufruídos em função do certificado, bem como quanto aos procedimentos contábeis adotados para apurar e evidenciar os seus impactos nas demonstrações contábeis, realizou-se uma pesquisa de caráter exploratório, por meio da aplicação de questionários.

Esses questionários enviados aos responsáveis técnicos do setor contábil das IESCEBAS, através dos quais se buscaram elementos que pudessem demonstrar os problemas levantados, principalmente no que diz respeito à Contabilidade dessas instituições.

O questionário elaborado foi enviado pelo correio, com envelope selado para resposta, para os Reitores e Diretores das IESCEBAS juntamente com correspondência do Reitor da Universidade Católica Dom Bosco solicitando que colaborassem com a pesquisa, dada a sua importância e pedindo ao responsável pelo setor contábil da instituição que preenchesse o questionário e o devolvesse.
O questionário foi dividido em duas partes para melhor compreensão dos resultados, sendo que a segunda parte foi dividida em três blocos.

Na primeira parte, procurou-se conhecer o perfil da instituição, tentando identificar o tempo de existência, quantidade de alunos e de cursos e como funciona o setor contábil.

A segunda refere-se, especificamente, ao certificado e divide-se em três blocos:

a) quanto à instituição: buscou-se saber a quanto tempo a instituição possui o certificado, quantidade de alunos atendidos em função do certificado, valor aplicado em beneficências e as áreas de atuação;

b) quanto aos benefícios: procurou-se constatar o conhecimento dos profissionais responsáveis com relação aos benefícios e obrigações em função do certificado; e

c) quanto às informações: tentou-se verificar como são contabilizados os fatos ocorridos em função do certificado, se o resultado entre as receitas e despesas são apurados e como são demonstradas as informações geradas.

Como a pesquisa está limitada às Instituições de Ensino Superior portadoras do Certificado de Entidades Beneficente de Assistência Social, buscou-se junto ao Conselho Nacional de Assistência Social - CNAS, órgão responsável pela emissão do certificado, a relação com todas as instituições de ensino superior com certificado no Brasil. De posse da resposta do CNAS, constatou-se a existência de 782 (setecentas e oitenta e duas) instituições estabelecidas no Brasil com certificado. Foram enviados, então, questionários para todas as instituições constantes do cadastro do CNAS.

Do total dos questionários enviados retornaram 103 (cento e três), dos quais:

- 28 (vinte e oito) são de IESCEBAS;

- 23 (vinte e três) não foram encontradas ou o endereço não conferia;

- 52 (cinqüenta e três) não são IESCEBAS.

Constatada a inconsistência no cadastro do CNAS, procurou-se verificar junto ao órgão o que realmente ocorrera, sendo informado de que não possui cadastro por segmento de atividade.

Deve-se registrar que a amostra trabalhada não foi, estatisticamente, determinada para produzir um resultado representativo do universo, podendo levar a conclusões enviesadas, visto não ser conhecido o total da população. 
A seguir, apresentam-se os resultados da pesquisa, sendo que somente a tabulação quanto às informações é que serão demonstradas em forma de tabelas. As tabelas contêm as freqüências e percentagens correspondentes às opções das questões objetivas.

\subsection{Quanto às instituições pesquisadas}

Constatou-se através das respostas que a maioria das instituições pesquisadas, ou seja, $96,43 \%$, já atuam no mercado há mais de 20 (vinte) anos e que 50\% já existem há mais de 40 (quarenta) anos. Esse fato demonstra que a maioria das instituições, que possuem o certificado, já está consolidada no mercado.

Com relação à quantidade de alunos, os resultados mostraram que $50 \%$ das instituições possuem mais de 5.000 alunos.

Verificou-se, através das respostas, que a maioria das instituições possui setor contábil próprio e que somente duas instituições das pesquisadas terceirizam a sua Contabilidade.

\subsection{Quanto aos benefícios}

Verificou-se, através das respostas, que a maioria absoluta das instituições já possui o certificado há mais de 05 (cinco) anos, que, em 2001, cada uma atendeu a mais de 1000 (mil) alunos e que 50\% das instituições aplicaram mais de cinco milhões de reais em beneficências durante o exercício de 2001.

Constatou-se, pois, que a totalidade das instituições pesquisadas reconhece o INSS como benefício em função do certificado, entretanto não existe clareza com relação aos outros benefícios. Os benefícios gerados pelo certificado são as contribuições para a seguridade social e que, de acordo com o Art. $22 \mathrm{e}$ 23 da Lei 8.212, são: INSS, Cofins e Contribuição Social Sobre Lucro Líquido.

Foi verificado que 5 (cinco) instituições responderam que os seus gastos foram menores que os benefícios usufruídos. De acordo com a legislação, os valores gastos com beneficências nunca podem ser inferiores ao valor dos benefícios usufruídos.

É possível que, em função das respostas obtidas, mesmo as instituições que responderam que os gastos foram inferiores aos benefícios, possam ter atendido à legislação, haja vista que se trata apenas dos benefícios específicos do certificado. Constatou- se, pois, a partir das respostas, que como a maioria das instituições gasta mais dos que os benefícios, e como consideram outros benefícios além dos específicos do certificado, que essas instituições estão gastando mais do que se exige, ou seja, o mesmo valor que se deixou de recolher com a seguridade social. Não se pode afirmar, entretanto, que estão aplicando mais do que o percentual exigido, haja vista que esse percentual pode não ser suficiente para atender ao dispositivo legal, ou seja, no mínimo igual aos benefícios usufruídos em função do certificado.

A pesquisa, também, mostrou o desconhecimento que algumas instituições têm com relação às obrigações que possuem para manter os benefícios do Certificado. De acordo com o Decreto ํㅡ 2.536, as instituições portadoras do certificado devem aplicar, anualmente, $20 \%$ da sua receita bruta total, excluídas somente as receitas com imobilizado, em beneficências. Esse desconhecimento pode estar trazendo prejuízos para a instituição. É claro que, se a instituição aplicar $20 \%$ em bolsas de estudo, estará também, dessa forma, cumprindo com a sua obrigação, entretanto, se possuir outros tipos de beneficências, estará, desse modo, gastando mais do que o necessário. Vale ressaltar que esses $20 \%$ devem ser superiores aos benefícios usufruídos, conforme determina a legislação.

\subsection{Quanto às informações}

Foram elaboradas questões com o intuito de se conhecerem os procedimentos utilizados pelas instituições quanto às beneficências realizadas e benefícios recebidos.

a) Como são contabilizadas as beneficências realizadas?

\section{TABELA 1 - Forma de contabilização das beneficências}

\begin{tabular}{lcc} 
Opções & Freq. Absoluta & Freq. Relativa \\
\hline Contas de Resultado & 22 & $78,57 \%$ \\
\hline Contas de Compensação & 10 & $35,71 \%$ \\
\hline Em branco & 1 & $3,57 \%$ \\
\hline Total & 33 & \\
\hline
\end{tabular}

As beneficências realizadas representam, na maioria dos casos, receitas que a instituição deixou de receber em função de uma obrigação para com o certificado. Verifica-se, pois, através das respostas, que não existe uniformidade nos procedimentos, sendo 
que a maioria contabiliza em contas de resultado e um percentual significativo de instituições contabiliza em contas de compensação. Esse procedimento, prejudica a comparação das demonstrações das instituições, haja vista a diferença de procedimentos no registro dos fatos.

b) Os custos com as beneficências são apurados?

\section{TABELA 2 - Apuração dos custos}

\begin{tabular}{lcc} 
Opções & Freq. Absoluta & Freq. Relativa \\
\hline Sim apuram custos & 20 & $71,43 \%$ \\
\hline Não apuram custos & 8 & $28,57 \%$ \\
\hline Total & 28 & $100,00 \%$ \\
\hline
\end{tabular}

A grande maioria respondeu que apura os custos, significando, dessa forma, que atribuem grande importância a esse item, porém existe um percentual elevado de instituições que não apuram seus custos deixando de prestar uma informação importantíssima para os dirigentes.

c) Como são contabilizados os benefícios obtidos com o Certificado?

\section{TABELA 3 - Forma de contabilização dos benefícios}

\begin{tabular}{lcc} 
Opções & Freq.Absoluta & Freq.Relativa \\
\hline Contas de resultados & 8 & $28,57 \%$ \\
\hline Contas de Compensação & 12 & $42,86 \%$ \\
\hline Não são contabilizados & 10 & $35,71 \%$ \\
\hline Total & 30 & \\
\hline
\end{tabular}

Novamente aqui, como ocorreu na questão forma de contabilização das beneficências, demonstradas na tabela 1, verifica-se que não existe uniformidade nos procedimentos, ocorrendo, aqui também, um contraste entre as respostas. Nas respostas apresentadas na tabela 1, observa-se que $75 \%$ dos contabilistas responderam que contabilizam as beneficências em contas de resultado; entretanto, de acordo com a tabela 3 , somente $28,57 \%$ contabilizam os benefícios em contas de resultado. A maioria contabiliza em contas de compensação e um número significativo de instituições não contabiliza. Esse fato contraria o princípio do confronto das despesas com as receitas e com os períodos contábeis.

d) O resultado da diferença entre as receitas e despesas do Certificado é apurado?
TABELA 4 - Apuração de resultado

\begin{tabular}{lcc} 
Opções & Freq. Absoluta & Freq. Relativa \\
\hline Sim apuram o resultado & 14 & $50,00 \%$ \\
\hline Não apuram o resultado & 14 & $50,00 \%$ \\
\hline Total & 28 & $100,00 \%$ \\
\hline
\end{tabular}

Constata-se, pois, através das respostas, que a metade das instituições não apuram o resultado entre as receitas e despesas com certificado. Essa resposta não guarda coerência com a resposta demonstrada na tabela 2 , visto que a maioria das instituições apura os custos com o certificado, entretanto, nem todas as instituições que apuram os custos apuram o resultado.

e) Se positivo, como são demonstrados?

TABELA 5 - Demonstração dos resultados

\begin{tabular}{lcc} 
Opções & Freq.Absoluta & Freq.Relativa \\
\hline DRE & 10 & $35,71 \%$ \\
\hline Notas explicativas & 23 & $82,14 \%$ \\
\hline Balanço & 4 & $14,29 \%$ \\
\hline Outros & 10 & $35,71 \%$ \\
\hline Total & 37 & \\
\hline
\end{tabular}

As respostas demonstram que a maioria das instituições apresenta o resultado com a beneficência em notas explicativas e esse fato contraria as respostas demonstradas através da tabela 4, em que metade das instituições respondeu que não apuram os custos com o certificado. Se não apuram os custos como podem apurar o resultado? O objetivo da questão foi verificar como as instituições demonstram o resultado com a beneficência, sendo permitida a resposta a mais de um item, quando esse fato ocorresse.

\section{CONCEITOS FUNDAMENTAIS PARA PROPOSIÇÃO DO MODELO}

Diante do que foi verificado na pesquisa empírica e pelos estudos realizados, constatou-se que o certificado gera impactos patrimoniais e econômicos nas instituições e que, na prática, a Contabilidade não tem apurado e evidenciado esses impactos.

Como ciência que registra e controla o patrimônio e as variações patrimoniais das entidades, a Contabilidade deve apurar e evidenciar esses impactos de forma a prover informações para a tomada de decisão.

Portanto, procura-se, nesse tópico, apresentar os conceitos fundamentais que sustentam a proposição 
de um modelo contábil que permita a apuração e evidenciação dos resultados das IESCEBAS, subsidiando, assim, os gestores, o governo e a sociedade na gestão dos recursos envolvidos com a certificação dessas instituições.

\subsection{Beneficências/Gratuidades}

As beneficências ou gratuidades são serviços que as instituições possuidoras do certificado de entidade beneficente de assistência social estão obrigadas a prestar à comunidade carente como forma de compensar os valores relativos à seguridade social não repassados para o Tesouro Nacional.

As beneficências, no caso das instituições objeto de estudo, ocorrem, na grande maioria, através da prestação de serviço escolar e clínica-escola à comunidade carente ou a quem dela necessitar. Para que essas prestações de serviço ocorram, são necessários sacrifícios de recursos por parte das instituições.

\subsection{Custos, Receitas, Ativos e Passivos}

Segundo Martins (2000, p.25), "Custo são gastos relativos a bem ou serviço utilizado na produção de outros bens ou serviços." Por esse entendimento, constata-se, pois, que as instituições, para colocar os serviços à comunidade, incorrem em custos. Como exemplo de custos, tem-se a mão-de-obra necessária para prestar serviços escolares e serviços nas clínicas-escolas. As beneficências são prestadas não por opção da instituição, mas por obrigação para a manutenção do certificado.

Esses serviços, conforme se pôde verificar nas demonstrações em análise, não estão sendo contabilizados em contas de resultados no grupo de receitas. Diante desse fato, necessário se faz serem resgatados os conceitos de receita na visão de diversos autores.

Segundo a Equipe de Professores da FEA/USP (1998, p.66): "Entende-se por receita a entrada de elementos para o ativo, sob a forma de dinheiro ou direitos a receber, correspondentes, normalmente, à venda de mercadorias, de produtos ou à prestação de serviços."
Verifica-se, assim, que no caso das beneficências prestadas pelas IESCEBAS não há, por parte de quem recebe os serviços, pagamento ou compromisso de pagamento, não ocorrendo, dessa forma, pelo menos nessa visão, a entrada de elementos para o ativo.

De acordo com o FASB - Financial Accounting Standards Board (apud SILVA, 2000, p.163):

Receitas são entradas ou outros aumentos de ativos de uma entidade ou liquidação de seus passivos (ou combinação de ambos), durante um período proveniente da entrega ou produção de mercadorias, prestação de serviços, ou outras atividades que constituem as principais ou centrais operações em andamento da entidade.

O conceito apresentado pelo FASB aproxima-se bem da situação que ocorre nas IESCEBAS, ficando claro que as beneficências são receitas para essas instituições, ocorrendo um aumento de ativo, que será compensado através da liquidação de seus passivos, que são as contribuições para a seguridade social.

O Conselho Federal de Contabilidade, através da Resolução no 750, de 29 de dezembro de 1993, que dispôs sobre os Princípios Fundamentais de Contabilidade (PFC), definiu:

Art. 9o As receitas e as despesas devem ser incluídas na apuração do resultado do período em que ocorrerem, sempre simultaneamente quando se correlacionarem, independentemente de recebimento ou pagamento.

Verifica-se, portanto, que as receitas e as despesas devem ser confrontadas no período em que ocorrerem. Nota-se que, não contabilizando as beneficências em contas de resultados e contabilizando os custos, essa confrontação não ocorre.

Diante dos conceitos apresentados, torna-se necessário a apresentação de alguns conceitos de ativo e passivo, com o intuito de contribuir para o entendimento do assunto.

Nesse aspecto, o FASB (apud HENDRIKSEN; VAN BREDA, 1999, p.283), através do SFAC 6, definiu ativos e passivos da seguinte forma: 
Ativos são benefícios econômicos futuros prováveis, obtidos ou controlados por uma dada entidade em conseqüência de transações ou eventos passados.

$$
[\ldots]
$$

Passivos são sacrifícios futuros prováveis de benefícios econômicos decorrentes de obrigações presentes de uma dada entidade, quanto à transferência de ativos ou prestação de serviços a outras entidades no futuro, em conseqüência de transações ou eventos passados.

ludícibus (2000, p.124) firma seu posicionamento concluindo que:

1. o ativo deve ser considerado à luz da sua propriedade e/ou à luz de sua posse e controle; normalmente as duas condições virão juntas;

2. precisa estar incluído no ativo, em seu bojo, algum direito específico a benefícios futuros [...], ou, em sentido mais amplo, o elemento precisa apresentar uma potencialidade de serviços futuros [...] para a entidade;

3. o direito precisa ser exclusivo da entidade; [...]

No que diz respeito ao passivo, ludícibus (2000, p.140-141) afirma:

1. As exigibilidades deveriam referir-se a fatos já ocorridos (transações ou eventos), normalmente a serem pagas em um momento específico futuro de tempo, podendo-se, todavia, reconhecer certas exigibilidades em situações que, pelo vulto do cometimento que podem acarretar para a entidade (mesmo que os eventos caracterizem a exigibilidade legal apenas no futuro), não podem deixar de ser contempladas. Poderiam estar incluídos nesta última categoria, digamos, o valor atual das indenizações futuras [...]

Pode-se perceber, com os conceitos anteriormente elencados, que as beneficências ou gratuidades apresentam características de ativos e passivos, pois a natureza dos fatos envolvidos é idêntica.

Quando a instituição faz a opção pelo certificado, passa a ter a obrigação de aplicar no mínimo $20 \%$ da receita bruta total em gratuidades ou beneficências. Ao realizar as gratuidades, a instituição estará gerando um ativo que irá amortizar o seu passivo, ou seja, as contribuições sociais não repassadas ao governo, em função de possuir o certificado.

Não considerar esses fatos pela Contabilidade, como foi constatado, significa desprezar a teoria contábil e também não conhecer sua realidade econômico-financeira.

\subsection{Custo de Oportunidade}

Antes de fazer a opção pelo certificado, as instituições devem proceder à escolha entre as alternativas existentes e esse fato é denominado de custo de oportunidade.

Diante de uma abordagem contábil, Horngren et al. (2000, p.277) definem que: "Custo de oportunidade é a contribuição para o lucro de que se abre mão pela não-utilização de um recurso limitado na sua melhor opção de uso".

Nesse sentido, Pereira (in: CATELLI, 2001, p.389) define:

Custo de oportunidade corresponde ao valor de um determinado recurso em seu melhor uso alternativo. Representa o custo da escolha de uma alternativa em detrimento de outra capaz de proporcionar um maior benefício, ou seja, é o custo da melhor oportunidade a que se renuncia quando da escolha de uma alternativa.

Partindo-se desse enfoque e sabendo-se que os problemas residem na tomada de decisões entre diversas alternativas, segundo o mesmo autor, "o custo de oportunidade expressa o benefício efetivamente obtido de uma decisão, considerando o melhor uso alternativo dos recursos envolvidos". Dessa forma, o autor define que uma decisão é decorrente "do confronto entre o benefício gerado pela alternativa escolhida e o benefício que seria obtido pela escolha da melhor alternativa abandonada", de onde advém o conceito de custo de oportunidade.

Percebe-se, dessa forma, que o custo de oportunidade é um conceito indispensável em todas as organizações e que também as IESCEBAS devem 
considerar esse aspecto quando da apuração do resultado do certificado.

Diante do que foi apresentado, para se obter o custo de oportunidade da alternativa de ter o certificado, deve-se realizar o confronto entre os benefícios gerados por ele e o benefício que seria obtido pela escoIha da alternativa abandonada, ou seja, a cobrança da mensalidade escolar e, nos casos em que existir, da prestação de serviços nas clínicas médicas.

Sobre essa questão, Morse e Roth (apud BEUREN, 1993, p.4) afirmam que "o custo de oportunidade do uso de um recurso de uma maneira é o recebimento líquido de caixa esperado que poderia ser obtido se o recurso fosse usado na outra ação alternativa mais desejável".

Exemplificando, suponha-se que em determinada instituição ocorra a seguinte situação:

Benefícios gerados pelo certificado ...

$1.000,00$

Benefícios da alternativa abandonada

$1.500,00$

No exemplo, o custo de oportunidade a ser considerado quando da apuração do resultado do certificado, já que a instituição fez a opção por ele, é de R\$ $1.500,00$ (um mil e quinhentos reais). Em termos de resultado, haveria um prejuízo para a instituição de $\mathrm{R} \$ 500,00$ (quinhentos reais) em função de ter feito a opção pelo certificado.
Nessa visão, comparando-se a alternativa aceita, ou seja, de ter o certificado com a rejeitada, de não receber pela prestação de serviços, obter-se-ão fortes elementos de análise para avaliar o desempenho da decisão. Esses elementos devem ser objeto de análise pelas IESCEBAS, governo e sociedade.

\section{MODELO PROPOSTO}

No modelo proposto de Demonstração do Resultado, são utilizados os conceitos de receitas, custos, despesas e custo de oportunidade, conforme apresentados na seção anterior.

Ao contabilizar as beneficências como receitas e as contribuições para seguridade social como custos e despesas, constata-se a aplicação do princípio da competência, em que as receitas são confrontadas com as despesas no período em que ocorrem.

A seguir, são apresentados os modelos propostos de demonstração do resultado global e com o certificado.

\subsection{Demonstração do Resultado}

Nessa demonstração, apresenta-se o resultado global segregado dos resultados com o certificado, de modo a evidenciar a sua contribuição para o resultado global da instituição.

\begin{tabular}{l|l}
\multicolumn{1}{c}{ Grupos de Contas } & \multicolumn{1}{c}{ Especificação } \\
Receita Operacional Bruta & $\begin{array}{l}\text { Mensalidades escolares, taxas diversas, bolsas de estudos, serviços de assistência } \\
\text { social e outros serviços prestados à sociedade. }\end{array}$ \\
\hline Deduções da Receita & Contribuições sociais incidentes sobre as prestações de serviços - Cofins. \\
\hline Receita Operacional Líquida & Receita Operacional Bruta diminuídas as deduções da receita. \\
\hline Custos dos Serviços Prestados & $\begin{array}{l}\text { Salários, encargos sociais, capacitação, atividades de extensão e demais gastos } \\
\text { relacionados à docência. }\end{array}$ \\
\hline Lucro Bruto & Receita Operacional Líquida menos os Custos dos Serviços Prestados. \\
\hline Despesas Operacionais & Despesas administrativas, resultado financeiro e despesas com provisões. \\
\hline Outras Receitas e & $\begin{array}{l}\text { Receitas e despesas que não são objeto da instituição, mas que em função da } \\
\text { Despesas Operacionais }\end{array}$ \\
\hline Resultado Operacional & $\begin{array}{l}\text { Resultado da atividade principal, comparando-se as receitas com os custos e despe- } \\
\text { sas operacionais. }\end{array}$ \\
\hline Resultado Não Operacional & Doações para custeio, resultado da alienação do ativo imobilizado. \\
\hline Resultado Antes da C.Social & Resultado apurado antes do cálculo da Contribuição Social. \\
\hline Contribuição Social & Contribuição para a seguridade social conforme Art. 23 da Lei no 8.212. \\
\hline Resultado Antes do Certificado & Resultado apurado sem os impactos do certificado. \\
\hline Resultado com certificado & Resultado apurado com o certificado de entidade beneficente de assistência social, \\
& comparando-se as receitas (benefícios recebidos) com os custos (beneficências \\
\hline Resultado do Exercício & realizadas). \\
\hline & Resultado do período, com os impactos do certificado.
\end{tabular}




\subsection{Demonstração do Resultado com Certificado}

O modelo proposto demonstra as receitas e custos ocorridos em determinado período, em função de a instituição possuir o certificado de entidade beneficente de assistência social. Há de se ressaltar que o modelo contempla, apenas, os valores tangíveis, não sendo considerados, dessa forma, valores intangíveis. O resultado positivo indica que a instituição não cumpriu a legislação, estando sujeita à perda do certifica- do e conseqüentemente do direito de usufruir os benefícios. O resultado negativo significa que a instituição aplicou mais recursos em beneficências do que recebeu de benefícios. Essa situação demonstra o quanto realmente a instituição praticou de filantropia, haja vista não poder considerar como filantropia o valor aplicado em beneficências com recursos da própria sociedade, ou seja, os valores não repassados pelo governo.

Abaixo é apresentado o modelo de demonstração do resultado com certificado:

\begin{tabular}{l|l}
\multicolumn{1}{c}{ DEMONSTRAÇÃo DO RESULTADO } \\
\hline \multicolumn{1}{c}{ Grupos de Contas } & \multicolumn{1}{c}{ Especificação } \\
Receitas do Certificado & $\begin{array}{l}\text { São considerados como receitas, para fins de apuração do resultado com o certificado, } \\
\text { as contribuições para a seguridade social (INSS, Cofins e CSLL). }\end{array}$ \\
\hline Custos do Certificado & $\begin{array}{l}\text { As bolsas de estudos e a assistência social prestada pelas IESCEBAS à sociedade } \\
\text { são consideradas como custos. }\end{array}$ \\
\hline Resultado do Exercício & Resultado apurado entre as receitas (benefícios) e os custos (beneficências).
\end{tabular}

\section{Quadro 3 - Modelo de Demonstração do Resultado com Certificado}

Para fins de apuração do resultado com o certificado, estão sendo utilizados os conceitos de custo de oportunidade, em que os custos (bolsas de estudo e assistência social) são a alternativa abandonada, e os benefícios são resultado da decisão tomada pela empresa.

De acordo com Mauro (1991, p.177):

o mercado se apresenta como o ponto de definição do valor dos itens transacionados, visto que os preços ali praticados induzem o produtor à venda e o comprador à compra, constituindose, sempre que possível, viável e factível na alternativa mais adequada a ser adotada como parâmetro de valor.

Apurar os resultados com base no custo de oportunidade, significa utilizar:

a) Bolsas de Estudo: valores de mensalidade praticados no mercado pela instituição para os respectivos cursos;

b) Assistência Social: valores praticados no mercado pela prestação de serviços nas diversas áreas da saúde, utilizando-se como base a tabela de preços editada pelos conselhos regionais da respectiva área de atuação; c) Benefícios: valores deixados de recolher para a seguridade social a título de: INSS, Cofins e CSLL, ou seja, os encargos que a empresa teria caso não tivesse os benefícios. Os valores descontados dos funcionários a título de INSS deverão ser recolhidos, normalmente, aos cofres do governo.

A apuração do resultado com o certificado, aplicando-se o conceito de custo de oportunidade, permite demonstrar o quanto a instituição recebeu de benefícios (receitas) e o quanto aplicou em beneficências (custos). Vale ressaltar que, de acordo com a legislação, o saldo apurado deve ser igual a 0 (zero) ou menor que 1 (um), indicando que a instituição aplicou o total dos benefícios recebidos. Se o saldo apurado for igual ou superior a 1 (um), significa que a instituição não aplicou o total dos recursos que deixou de recolher para o governo em contribuições para a seguridade social em beneficências, descumprindo, dessa forma, a legislação.

O resultado apurado, conforme se pode verificar, é integrado à Demonstração de Resultado. Há de se ressaltar que a inclusão do resultado com o certificado na Demonstração de Resultados da instituição não modifica o seu resultado global. Isso ocorre porque, ao contabilizar as Beneficências como receitas da entidade, os encargos com a seguridade social como despesas e a utilização do custo de oportunidade para 
apurar o resultado do certificado, o saldo do confronto entre esses registros sempre será igual a zero. Deixando de contabilizar essas receitas e despesas, entretanto contabilizando os custos e despesas que ocorreram para a realização das beneficências, a instituição já contempla os impactos do certificado e a conseqüente manutenção dos benefícios, no resultado. Dessa forma, entretanto, não é demonstrado pela Contabilidade qual o valor desses impactos.

\subsection{LANÇAMENTOS CONTÁBEIS}

A seguir, apresenta-se uma proposta de lançamentos contábeis para tratamento dos impactos econômicos derivados da certificação da instituição, de modo a permitir a apuração e evidenciação dos seus resultados, conforme discutidos no tópico anterior:

a) Contabilização da Obrigação: à medida que a instituição realize receitas, constitui-se uma obrigação, ou seja, de aplicar pelo menos $20 \%$ (vinte por cento) do valor da receita em gratuidades. Essa obrigação gera um direito para a instituição de não recolher o mesmo valor para a seguridade social.

Contribuições Sociais a Utilizar (Ativo)

a Beneficências a Realizar (Passivo)

b) Contabilização das Gratuidades/Beneficências: realizando gratuidades/ beneficências, ou seja, dando bolsas de estudos aos alunos ou prestando atendimentos assistenciais à população carente, a instituição contabiliza esses valores como receita da sua atividade, utilizando-se como parâmetro o preço de transferência baseado no custo de oportunidade, tendo como contrapartida a conta do Passivo em que está registrada a sua obrigação de prestar esse serviço. Registra-se, também, esse valor em uma conta de resultado com custo do certificado, com a finalidade de apurar o seu resultado, visto que se trata de um sacrifício da instituição para a manutenção dos benefícios, tendo como contrapartida uma conta de Passivo, com a finalidade de evidenciar o saldo da obrigação.

Gratuidades/Beneficências a Realizar (Passivo) a Bolsas de Estudo (Receita)
Gratuidades/Beneficências a Realizar (Passivo) a Assistência Social (Receita)

Custos do Certificado (Custos) a Beneficências Realizadas (Passivo)

c) Contabilização dos Benefícios: Os benefícios (INSS, Cofins e CSLL) não recolhidos ao governo são registrados como custo ou despesa dependendo da sua natureza, tendo como contrapartida conta do Ativo. Também são registrados como receita, com a finalidade de apurar-se o resultado com o certificado, tendo como contrapartida conta do Ativo, com o objetivo de evidenciar o saldo que a instituição possui de benefícios.

Seguridade Social (Custo ou Despesa)

a Contribuições Sociais a Utilizar (Ativo)

Seguridade Social Utilizada (Ativo)

a Receita do Certificado (Receita)

d) Encerramento das Contas Patrimoniais: O encerramento das contas patrimoniais é efetuado, porque os saldos não são transferidos para o próximo exercício.

1) Saldo de Beneficências maior que Seguridade Social

Beneficências Realizadas (Passivo)

a Seguridade Social Utilizada (Ativo)

Beneficências Realizadas (Passivo)

a Seguridade Social a Utilizar (Ativo)

2) Saldo de Beneficências menor que Seguridade Social

Beneficências Realizadas (Passivo)

a Seguridade Social Utilizada (Ativo)

Beneficências a Realizar (Passivo)

a Seguridade Social a Utilizar (Ativo).

As contas Beneficências Realizadas e Seguridade Social são confrontadas, sendo que o 
saldo se credor é transferido para a conta Seguridade Social a Utilizar e, quando inverso, ou seja, devedor, é transferido para a conta Beneficências a Realizar. Isso significa que, quando a instituição tem saldo credor, ela realizou mais beneficências do que usufruiu benefícios, sendo que, quando o saldo é devedor, ocorre o contrário, ou seja, a instituição obteve mais benefícios do que aplicou em beneficências.

\section{APLICAÇÃO DO MODELO PROPOSTO}

Diante do exposto, apresenta-se, a seguir (tabelas 6 e 7), uma aplicação do modelo proposto ao caso de uma instituição de ensino superior certificada, utilizando-se dados reais extraídos das Demonstrações dos Resultados da PUC/Rio referentes aos exercícios de 2000 e 2001 :

Tabela 6- Demonstração do Resultado da PUC/Rio, com aplicação do modelo proposto - Exercícios de 2000/2001 FACULDADES CATÓLICAS - PUC/RIO

\begin{tabular}{|c|c|c|}
\hline DEMONSTRAÇÃO DO RES & $\frac{\text { Í́ODO DE 01/01 }}{2001}$ & 2000 \\
\hline \multicolumn{3}{|l|}{ RECEITA OPERACIONAL BRUTA } \\
\hline \multicolumn{3}{|l|}{ SERVIÇOS } \\
\hline ESCOLARES & $91.946 .378,00$ & $84.220 .755,00$ \\
\hline OUTROS SERVIÇOS & $11.597 .726,00$ & $10.812 .241,00$ \\
\hline \multicolumn{3}{|l|}{ GRATUIDADES } \\
\hline BOLSAS DE ESTUDO & $21.951 .178,00$ & $21.268 .838,00$ \\
\hline ASSISTÊNCIA SOCIAL & $11.008 .190,00$ & $13.274 .000,00$ \\
\hline TOTAL RECEITAS DE SERVIÇOS & $136.503 .472,00$ & $129.575 .834,00$ \\
\hline \multicolumn{3}{|l|}{ DEDUÇÕES DA RECEITA } \\
\hline COFINS & $4.095 .104,16$ & $3.887 .275,02$ \\
\hline RECEITA OPERACIONAL LÍQUIDA & $132.408 .367,84$ & $125.688 .558,98$ \\
\hline CUSTOS DOS SERVIÇOS PRESTADOS & $42.426 .099,00$ & $38.635 .427,00$ \\
\hline SALÁRIOS & $31.310 .774,00$ & $28.513 .230,00$ \\
\hline ENCARGOS SOCIAIS & $11.115 .325,00$ & 10.122.197,00 \\
\hline ATIVIDADES DE EXTENSÃO & 0,00 & 0,00 \\
\hline CAPACITAÇÃO DE PESSOAL & 0,00 & 0,00 \\
\hline LUCRO BRUTO & $89.982 .268,84$ & $87.053 .131,98$ \\
\hline DESPESAS OPERACIONAIS & $86.292 .146,00$ & $76.786 .022,00$ \\
\hline ADMINISTRATIVAS & $84.546 .732,00$ & $73.828 .646,00$ \\
\hline ENCARGOS FINANCEIROS LÍQUIDOS & $(2.535 .924,00)$ & $(1.429 .572,00)$ \\
\hline DESPESAS COM PROVISÕES & $4.281 .338,00$ & $4.386 .948,00$ \\
\hline OUTRAS RECEITAS E DESPESAS OPERACIONAIS & $1.403 .385,00$ & $1.247 .310,00$ \\
\hline PATRIMONIAIS & $1.403 .385,00$ & $1.247 .310,00$ \\
\hline RESULTADO OPERACIONAL & $5.093 .507,84$ & 11.514.419,98 \\
\hline RESULTADO NÃO OPERACIONAL & $9.493 .946,00$ & $6.945 .070,00$ \\
\hline RECEITAS NÃO OPERACIONAIS & $9.493 .946,00$ & $6.945 .070,00$ \\
\hline DESPESAS NÃO OPERACIONAIS & 0,00 & 0,00 \\
\hline GANHOS/PERDAS C/ ATIVO IMOBILIZADO & 0,00 & 0,00 \\
\hline RESULTADO ANTES DA C. SOCIAL & $14.587 .453,84$ & $18.459 .489,98$ \\
\hline CONTRIBUIÇÃO SOCIAL & $1.312 .870,85$ & $1.661 .354,10$ \\
\hline RESULTADO ANTES DO CERTIFICADO & $13.274 .582,99$ & $16.798 .135,88$ \\
\hline RESULTADO COM CERTIFICADO & $(10.246 .022,99)$ & $(12.513 .995,88)$ \\
\hline RECEITAS DO CERTIFICADO & $22.713 .345,01$ & $22.028 .842,12$ \\
\hline CUSTOS DO CERTIFICADO & $32.959 .368,00$ & $34.542 .838,00$ \\
\hline RESULTADO DO EXERCÍCIO & $3.028 .560,00$ & 4.284.140,00 \\
\hline
\end{tabular}


Tabela 7- Demonstração do Resultado com o Certificado da PUC/Rio, conforme o modelo proposto Exercícios de 2000/2001

FACULDADES CATÓLICAS - PUC/RIO

\begin{tabular}{|c|c|c|}
\hline \multicolumn{3}{|c|}{$\begin{array}{c}\text { DEMONSTRAÇÃO DO RESULTADO COM CERTIFICADO } \\
\text { DO PERÍODO DE 01/01 A } 31 / 12\end{array}$} \\
\hline & 2001 & 2000 \\
\hline \multicolumn{3}{|l|}{ RECEITAS DO CERTIFICADO } \\
\hline INSS & $17.305 .370,00$ & $16.480 .213,00$ \\
\hline COFINS & $4.095 .104,16$ & $3.887 .275,02$ \\
\hline C.SOCIAL & $1.312 .870,85$ & $1.661 .354,10$ \\
\hline TOTAL RECEITAS & 22.713.345, 01 & $22.028 .842,12$ \\
\hline \multicolumn{3}{|l|}{ CUSTOS DO CERTIFICADO } \\
\hline BOLSAS DE ESTUDO & $21.951 .178,00$ & $21.268 .838,00$ \\
\hline ASSISTÊNCIA SOCIAL & $11.008 .190,00$ & $13.274 .000,00$ \\
\hline TOTAL CUSTOS & $32.959 .368,00$ & $34.542 .838,00$ \\
\hline RESULTADO DO EXERCÍCIO & $(10.246 .022,99)$ & $(12.513 .995,88)$ \\
\hline
\end{tabular}

Os resultados demonstram que, nos anos de 2000 e 2001, a PUC/Rio efetuou filantropia, haja vista a instituição ter aplicado R\$ 12.513.995,88 (doze miIhões, quinhentos e treze mil, novecentos e noventa e cinco reais e oitenta e oito centavos) e $\mathrm{R} \$$ 10.246.022,99 (dez milhões, duzentos e quarenta e seis mil, vinte e dois reais e noventa e nove centavos) nos anos de 2000 e 2001 respectivamente, a mais do que recebeu de benefícios, ou seja, isenção da seguridade social, no mesmo período.

A tabela 6 apresenta o resultado global da instituição, na qual o resultado com o certificado é segregado sem, contudo, alterar o seu resultado final. No ano de 2001, o resultado da instituição sem considerar os efeitos do certificado foi de $R \$ 13.274 .582,99$. O resultado do certificado foi negativo de $\mathrm{R} \$$ 10.246.022,99, demonstrando que a instituição aplicou mais recursos do que obteve de benefícios fiscais com o certificado. Somando-se ambos os resultados, obtêm-se o resultado global da instituição, que foi de $R \$ 3.028 .560,00$ no período.

A tabela 7 detalha o resultado obtido com o certificado. Nota-se, por exemplo, que o resultado com o certificado, em 2001, no valor de $\mathrm{R} \$ 10.246 .022$,99, é formado pela diferença entre as receitas (benefícios fiscais obtidos com as isenções) de $\mathrm{R} \$ 22.713 .345,01$ e os custos (gratuidades) de $R \$ 32.959 .368,00$. DetaIhando-se um pouco mais as receitas, nota-se que a instituição obteve isenções fiscais relativas a INSS, COFINS e Contribuição Social, cujos valores correspondem, respectivamente, a $\mathrm{R} \$ 17.305 .370,00$, $R$ \$ 4.095.104,16 e $R$ \$ 1.312.870,85. Com relação aos custos, evidencia-se que a instituição ofereceu gratuitamente à sociedade bolsas de estudos que correspondem ao valor de $\mathrm{R} \$ 21.951 .178,00 \mathrm{e}$ prestou serviços assistenciais no valor de $\mathrm{R} \$ 11.008 .190,00$.

Nos dois períodos analisados (2000 e 2001), notase, pelos resultados apresentados com a aplicação do modelo proposto, que a instituição cumpriu o seu papel de instituição filantrópica, aplicando mais recursos do que obteve de benefícios fiscais com o certificado. A informação sobre o resultado obtido com o certificado mostra-se como uma informação útil e relevante, tanto para fins de gestão da instituição, quanto para servir como um mecanismo de controle para o governo e proporcionar maior transparência para a sociedade.

\section{CONCLUSÕES}

Ao longo deste trabalho, procurou-se abordar o tema em estudo de forma a dar sustentação à solução proposta. No que tange à questão principal do estudo, constatou-se que a Contabilidade pode apurar e evidenciar os resultados com o certificado de maneira a subsidiar a gestão das IESCEBAS, o governo e a sociedade na tomada de decisão. A Contabilidade, como ciência, possibilita à sociedade, através dos seus instrumentos, conhecer a forma, como e onde os recursos estão sendo aplicados, desde que realizada de modo correto. Desse modo, comprovase a hipótese levantada preliminarmente, posto que se constatou que o certificado gera resultados (e não apenas custos) para as instituições e que eles 
podem ser apurados e evidenciados pela Contabilidade das IESCEBAS. No que se refere ao objetivo estabelecido, conclui-se que a proposta apresentada para a Demonstração de Resultado das IESCEBAS contribui para a melhoria das informações contábeis, evidenciando, de forma transparente, os custos e benefícios da certificação dessas entidades.

A pesquisa de campo realizada indicou que a forma como as instituições utilizam a Contabilidade não são suficientes para que os gestores, governo e a sociedade conheçam como estão sendo aplicados os recursos. O governo através do CNAS concede benefícios, mas não possui instrumentos eficientes de controle; as instituições têm o certificado, mas não sabem se é vantagem ou não mantê-lo; e a sociedade não tem nenhuma informação de como e onde os recursos de que abriu mão por meio das isenções estão sendo aplicados.

Por outro lado, o modelo proposto reconhece as receitas e despesas de acordo com os princípios fundamentais de Contabilidade, principalmente no que diz respeito ao princípio da competência. O modelo permite, ainda, que a instituição verifique como seria o resultado sem o certificado e quais os seus impactos no patrimônio da entidade.

A evidenciação do resultado com o certificado, conforme proposto, permite à sociedade e ao governo conhecer o quanto está se gastando com o que se deixou de recolher, se está ou não fazendo filantropia, e torna-se também um importante instrumento de marketing para as instituições, quando, é claro, investem mais do que estão obrigadas. Permite, igualmente, que os gestores conheçam através da Contabilidade qual é a real situação da instituição em determinado momento. $\mathrm{O}$ modelo permite conhecer o valor que a instituição tem que aplicar em beneficências, o quanto já aplicou e se está cumprindo o que está estabelecido em lei.

A proposta representa uma alternativa para se atender, por meio da Contabilidade, às necessidades de informação do governo, dos gestores e da sociedade. Ressalte-se, contudo, a importância para a sociedade conhecer - de forma clara e transparente como, quando e onde estão sendo aplicados os recursos que deveriam ser repassados ao governo e que, no entanto, são confiados a essas entidades.

Através do presente estudo, pôde-se constatar a necessidade de ampliação da pesquisa, principalmente no que diz respeito aos aspectos intangíveis gerados pelo certificado e também para que possa ser verificada qual a contribuição que essas instituições trazem para a sociedade, ou seja, se é vantagem ou não para o governo confiar a essas instituições a administração desses recursos ou, ainda, se haveria alternativas economicamente mais viáveis. Cabe-nos, portanto, o papel de realizar estudos e pesquisas que possam validar ou não os instrumentos utilizados na dinâmica das organizações com o propósito de contribuir para uma maior valorização da Contabilidade no contexto social.

BIBLIOGRAFIAS

BEUREN, Ilse Maria. Conceituação e contabilização do custo de oportunidade. Caderno de Estudos FIPECAFI. $\mathrm{n}^{\circ} 08$, São Paulo, p. 1-12, abril de 1993.

BRASIL. Constituição de 1988: Constituição Federal. Organizador: Pedro de Milanélo Piovezane; Coordenadora: Dulce Eugênia de Oliveira. 4 ed. São Paulo: Rideel, 1999.

Decreto no 2.536, de 6 de abril de 1998. Dispõe sobre a concessão do Certificado de Entidade de Fins Filantrópicos a que se refere o inciso IV do art. 18 da Lei 8742 , de 7 de Dezembro de 1993, e dá outras providências. Disponível em: $<$ wwwt.senado.gov.br/legbras/>.

Decreto no 4.499 , de 4 de dezembro de 2002. Altera o Art. $3^{\circ}$ do Decreto no 2.536, de 6 de Abril de 1998. Disponível em: <wwwt.senado.gov.br/legbras/>.

Lei $n=8.212$, de 24 de julho de 1991. Dispõe sobre a organização da Seguridade Social, institui Plano de Custeio e dá outras providências. Disponível em: <ht t p://w w w t.senado.gov.br/servlets/ NJUR.Filtro?tipo=LEI\&secao=NJUILEGBRAS\&numLe...> Acesso em: 24 jan. 2002.

Resolução CFC no 750/1993. In: CONSELHO FEDERAL DE CONTABILIDADE - CFC. Princípios Fundamentais de Contabilidade e Normas Brasileiras de Contabilidade. Brasília, CFC, 1999.

CATELLI, Armando. Controladoria - uma abordagem da gestão econômica GECON. 2 ed. São Paulo: Atlas, 2001.

CONSELHO FEDERAL DE CONTABILIDADE - CFC. Princípios Fundamentais de Contabilidade e Normas Brasileiras de Contabilidade. Brasília: CFC, 1999.

EQUIPE DE PROFESSORES FEA/USP. Contabilidade introdutória. 9 ed. São Paulo: Atlas, 1998.

HENDRIKSEN, Eldon S.; VAN BREDA, Michael F. Teoria da Contabilidade. São Paulo: Atlas, 1999. 
HORNGREN, Charles T. et al. Contabilidade de Custos. Rio de Janeiro: LTC, 2000.

IUDíCIBUS, Sérgio de. Teoria da contabilidade. São Paulo: Atlas, 2000.

MARTINS, Eliseu. Contabilidade de custos. São Paulo: Atlas, 2000.

MARTINS, Gilberto de Andrade; LINTZ, Alexandre. Guia para elaboração de monografias e trabalhos de conclusão de curso. São Paulo: Atlas, 2000.

MAURO, Carlos Alberto. Preço de transferência baseado no custo de oportunidade: Um instrumento para promoção da efi- cácia empresarial. 1991. 204 p. Dissertação (Mestrado em Controladoria e Contabilidade) - Faculdade de Economia, Administração e Contabilidade da Universidade de São Paulo. São Paulo.

POPPER, Karl. A lógica da pesquisa científica. 9. ed. São Paulo: Cultrix, 1993.

SILVA, Alexandre dos Santos. Análise das formas de reconhecimento da receita na contabilidade: Um enfoque no conceito econômico de lucro. 2000. 308 p. Dissertação (Mestrado em Gestão Universitária) - Instituto de Estudos e Projetos de Educação Superior da Universidade São Marcos. São Paulo.

\section{NOTA:}

Endereço dos autores:

Emanoel Marcos Lima

Soc. de Ensino Superior Estácio de Sá

BR 163, n. 3203 - Universitária

Campo Grande - MS

79.063-000

Carlos Alberto Pereira

FEA-USP

Av. Prof. Luciano Gualberto, 908 - prédio 3

Cidade Universitária

São Paulo - SP

05508-900 